\title{
Retrospective analysis for detecting seismic precursors in groundwater argon content
}

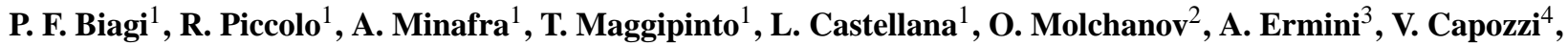 \\ G. Perna ${ }^{4}$, Y. M. Khatkevich ${ }^{5}$, and E. I. Gordeev ${ }^{5}$ \\ ${ }^{1}$ Department of Physics-INFM, University of Bari, Via Amendola 173, 70126 Bari, Italy \\ ${ }^{2}$ United Institute of the Earth's Physics, Russian Academy of Science, Bolshaya Gruzinskaya 10, 123995 Moscow, Russia \\ ${ }^{3}$ Department of Physics and Energy Science and Technology, University of Rome Tor Vergata, Via di Tor Vergata, 00133 \\ Rome, Italy \\ ${ }^{4}$ Department of Biomedical Sciences-INFM, University of Foggia, Via L. Pinto, 71100 Foggia, Italy \\ ${ }^{5}$ Experimental and Methodical Seismological Department, Geophysical Service, Russian Academy of Science, Pijp Av. 9, \\ 683006 Petropavlovsk-Kamchatsky, Russia
}

Received: 19 May 2003 - Revised: 17 October 2003 - Accepted: 20 October 2003 - Published: 1 March 2004

\begin{abstract}
We examined the groundwater Argon content data sampled from 1988 to 2001 at two wells in Kamchatka (Russia) and anomalous increases appeared clearly during JuneJuly 1996. On 21 June, a shallow $(1 \mathrm{~km})$ earthquake with $M=7.1$ occurred at a distance less than $250 \mathrm{~km}$ from the wells and so the previous increases could be related to this earthquake and, in particular, could be considered premonitory anomalies. In order to support this raw interpretation, we analysed the data collected in details. At first we smoothed out the high frequency fluctuations arising from the errors in a single measurement. Next we considered the known external effects on the water of a well that are the slow tectonic re-adjustment processes, the meteorology and the gravity tides and we separated these effects applying band-pass filters to the Argon content raw trends. Then we identified the largest fluctuations in these trends applying the $3 \sigma$ criterion and we found three anomalies in a case and two anomalies in other case. Comparing the time occurrence of the anomalies at the two wells we found out that a coincidence exists only in the case of the premonitory anomalies we are studying. The simultaneous appearance of well definite anomalies in the residual trends of the same parameter at two different sites supports their meaning and the possibility that they are related to some large scale effect, as the occurrence of a strong earthquake. But, other earthquakes similar to the June 1996 event took place during the Argon content measurements time and no anomaly appeared in this content. In the past, some of the authors of this paper studied the Helium content data collected in three natural springs of the Caucasus during seven years. A very similar result, that is the simultaneous appearance of clear premonitory anomalies only on the occasion of a strong $(M=7.0)$ but
\end{abstract}

Correspondence to: P. F. Biagi

(biagi@fisica.uniba.it) shallow $(2-4 \mathrm{~km})$ earthquake, was obtained. The correspondence with the case of the Caucasus validates the interpretation of the Kamchatkian anomalies as precursors.

\section{Introduction}

The Kamchatka peninsula, located in the far East of Russia, is characterised by frequent and strong seismic activity (magnitudes up to 8.6). The majority of earthquakes occur in a zone located offshore $60-100 \mathrm{~km}$ southeast of the Pacific coast of the peninsula (Fig. 1) with focal depths up to $650 \mathrm{~km}$ (Gorbatov et al., 1997). For many years, samples for hydrogeochemical analyses have been collected, with a mean sampling frequency of three days, in the form of the most common ions and gases in the groundwater of some deep wells and springs located in the southern area of the Kamchatka peninsula, where the capital city Petropavlovsk is located. The presence of possible precursors in the groundwater ions content on the occasion of the strongest earthquakes occurred in the area has been reported in Biagi et al. (2000). On 21 June 1996 a shallow (1 km) earthquake with $M=7.1$ occurred at a distance of about $200 \mathrm{~km}$ from Petropavlovsk (Fig. 1). After its occurrence clouding of surface waters and local trilling of the sea were observed and afterwards strong seismic crises $(4.0 \leq M \leq 6.0)$ happened for more than two months, defining a wide and surface rupture zone. On this occasion, a very clear increase of Argon gas content in the groundwater of two wells $\left(W_{2}\right.$ and $\left.W_{3}\right)$ located in Petropavlovsk area was observed. The content of the $\mathrm{Ar}$ gon dissolved in the water, after thermovacuum degassing, is measured with a $5 \%$ accuracy by means of gas chromatography. The location of the wells is shown in Fig. 1. Details of drilling date, depth and cross-section of the wells are given in Table 1 . The possibility that the Argon increase at $W_{2}$ could 
Table 1. Drilling time, depth and cross-section of the two wells indicated in Fig. 1.

\begin{tabular}{|c|c|c|c|c|}
\hline Well & Drilling & Depth (m) & & Cross-section \\
\hline$W_{2}$ & 1983 & 600 & $\begin{array}{r}0-36 \mathrm{~m} \\
36-600 \mathrm{~m}\end{array}$ & $\begin{array}{l}\text { rubbly-pebbled deposits } \\
\text { tuff }\end{array}$ \\
\hline$W_{3}$ & 1971 & 1208 & $\begin{array}{r}0-70 \mathrm{~m} \\
70-1208 \mathrm{~m}\end{array}$ & $\begin{array}{l}\text { gravelly-pebbled deposits } \\
\text { succession of andesites, rhyolites and tuffs }\end{array}$ \\
\hline
\end{tabular}

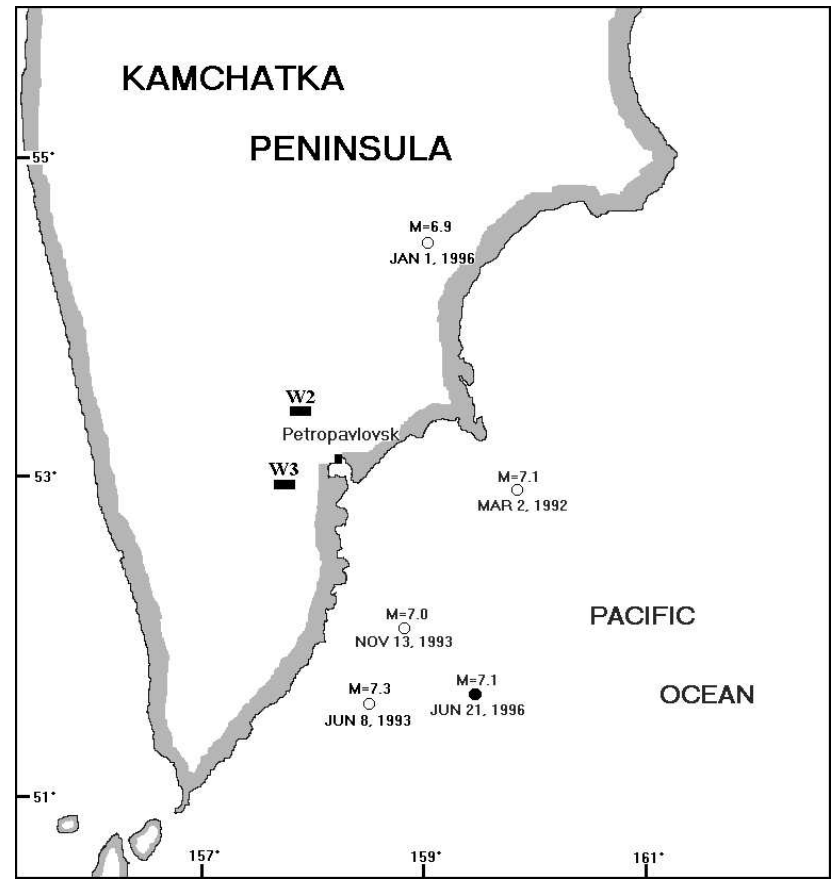

Fig. 1. Map showing the southern part of Kamchatka peninsula and the location of the wells $\left(W_{2}\right.$ and $\left.W_{3}\right)$ where the Argon data are collected. The dark circle indicates the epicentre of the 21 June 1996 earthquake. The white circles represent the other strong earthquakes which occurred in the zone during the Argon content measurement time. Occurrence dates and earthquakes magnitude are also reported.

be a precursor of the previous earthquake was preliminary presented by Biagi el al. (1999). Here we present the result of a retrospective analysis of the Argon content data collected from 1988 to 2001 at the two previous wells in order to specify the presence of a premonitory behaviour.

\section{Analysis}

At first, let us consider the data collected at $W_{3}$. First, tacking into account that the data are collected with a mean sampling frequency of three days, we derived a data set with one value per day by a linear interpolation of the raw data. This procedure does not change in any way the experimental trend; it allows only to obtain an equal spaced in time data set. Figure 2a shows the trend of the Argon content at $W_{3}$ we obtained from 15 October 1988 to 30 June 2001. Secondly, in order to reduce the effect of the variations due to a single measurement and the effect of the rapid variations, we applied a low-pass FFT filter to the data with a smoothing window of ten days. This smoothed trend is shown in Fig. 2b. This last procedure reduces only the noise existing in the unfiltered trend (Fig. 2a), but it does not change the main side of this trend. In both the Figs. 2 the Argon content increase mentioned in the previous session appears clearly. Then we considered the known external effects on the water of wells, i.e. the slow tectonic re-adjustment processes, the meteorology and the gravity tides (Barsukov et al., 1979; Barsukov et al., 1984, 1985; King et al., 1981; King, 1986; Thomas, 1988; Wakita et al., 1988) and we separated these effects in the Argon content smoothed trend. The meteorological components are mainly related to the surface-water flow and to the atmospheric contribution. For the long processes we applied a 36 months low-pass filter. For the meteorology we applied two band-pass filters: 10-14 months (annual) and 110-130 days (seasonal). For the gravity tides we applied three band-pass filters: 170-200 days (solar semiannual $=182.7$ days), $26-30$ days (lunar monthly $=27.55$ days) and $13-15$ days (lunar semi-monthly $=13.66$ days). These filtered trends are shown in Fig. 3. Adding these filtered trends we obtained the long-meteo-tidal time-series of the Argon content (Fig. 4b) that can be assumed as the background trend. In Fig. 4a the smoothed time-series of Argon content (the same of Fig. 2b) is shown. Then we obtained the residual trend subtracting this background trend from the starting smoothed trend of the Argon content. This residual trend is shown in Fig. 4c.

At this point, we carried out the normal distribution fitting on the data of the residual trend in order to test the significance level of this distribution. The fittings were made using the Shapiro-Wilk normality test and no significance level of a normal distribution fitting appeared. This result indicates that the residual trend we obtained is not a totally random sample. So, other external effects on the water of the well exist but they cannot be separated using pass filters or other analysis methods. The only further possibility of analysis is to identify the largest fluctuations and, at this purpose, at first we calculated the standard deviation $\sigma$ over the sample of the residual Argon content data and then we applied the $3 \sigma$ criterion. The $\pm 3 \sigma$ level is indicated in Fig. $4 \mathrm{c}$ by horizontal 


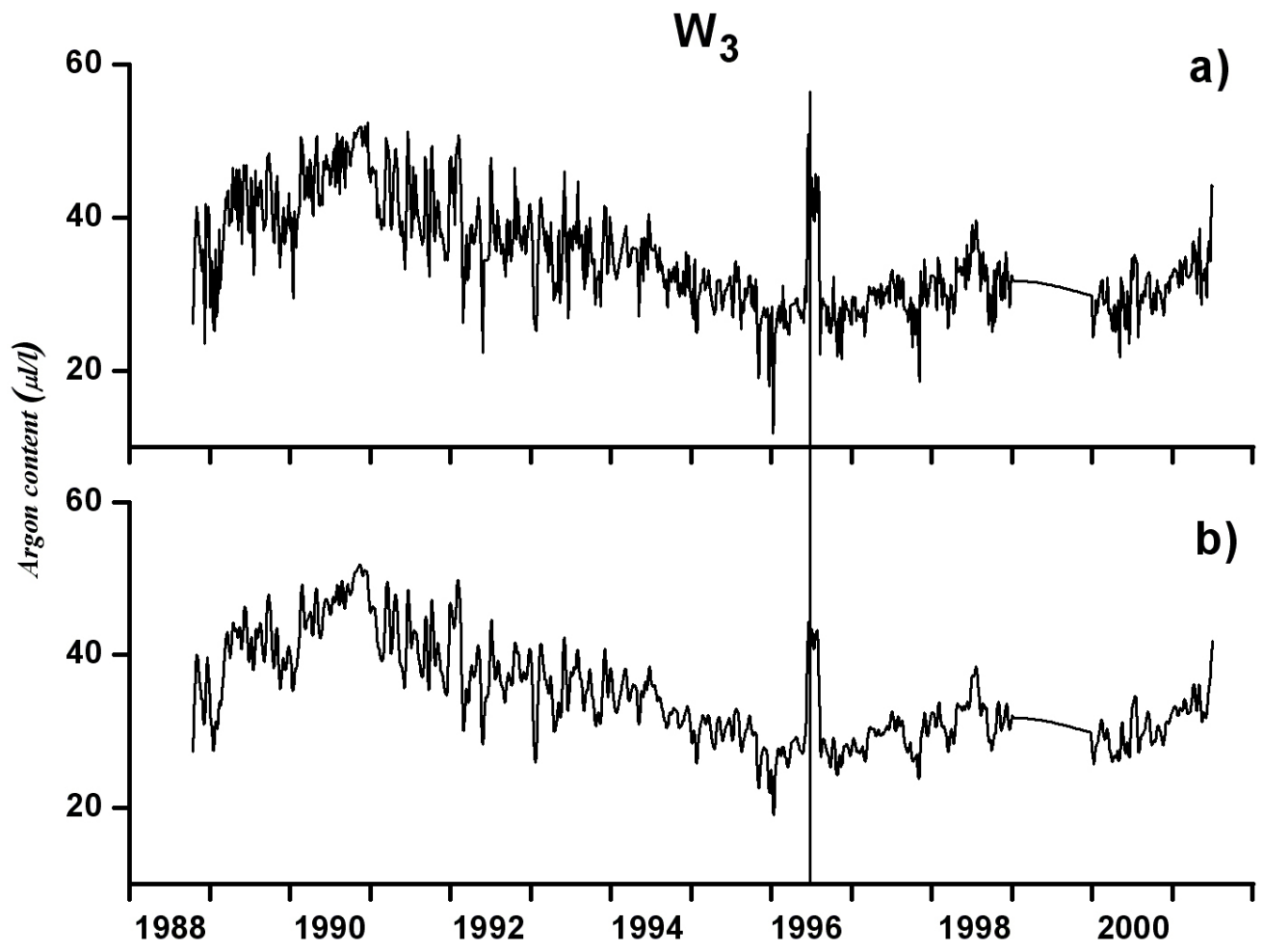

Fig. 2. (a) Time-series (one value per day) of Argon content at $W_{3}$ from 15 October 1988 to 30 June 2001. (b) Time-series of the previous data smoothed with a smoothing window of ten days. The vertical line indicates the occurrence of the 21 June 1996 earthquake.
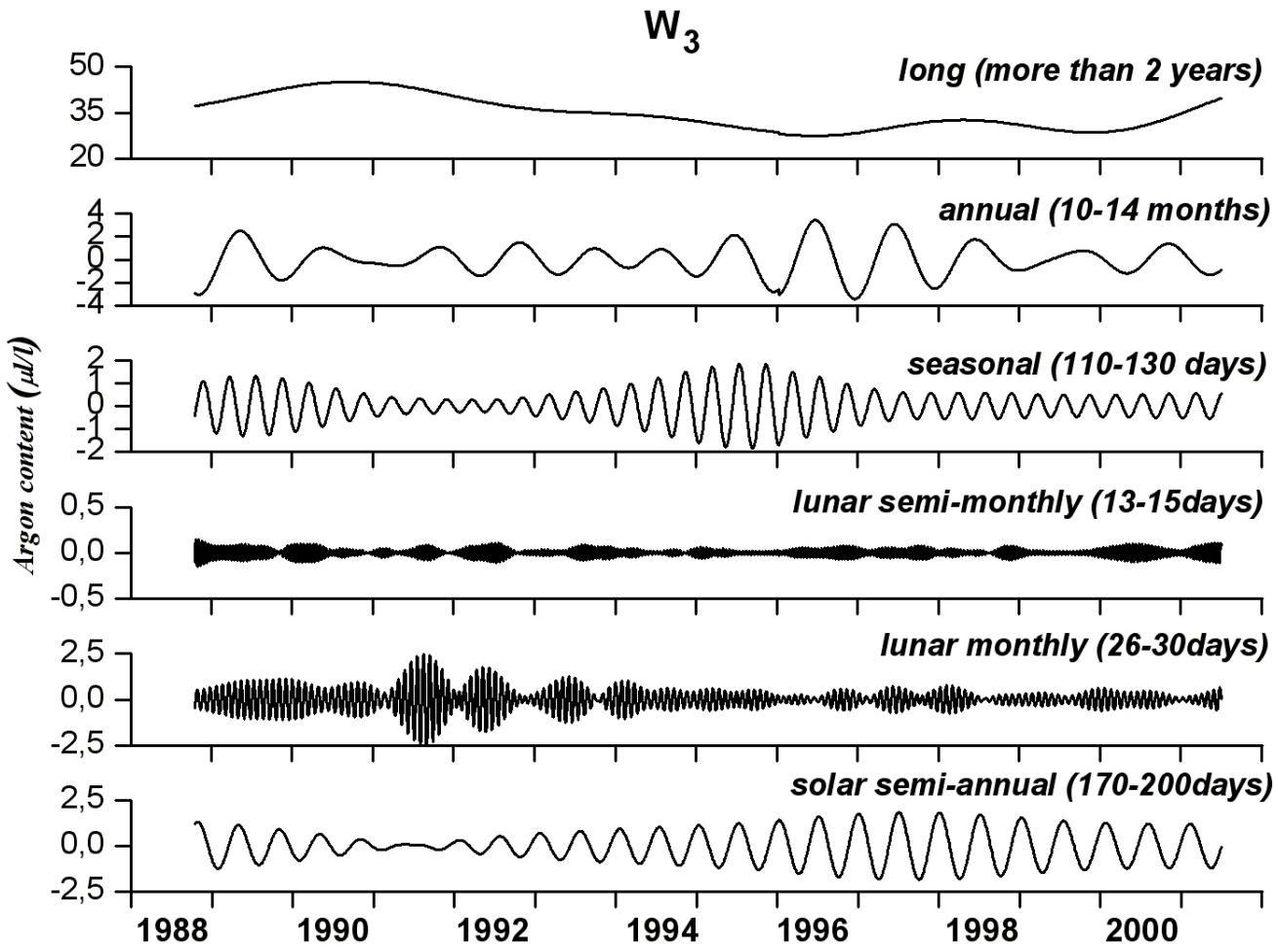

Fig. 3. From the top downwards, low-pass filtered trend and the band-pass filtered trends of the time-series reported in Fig. $2 b$. 


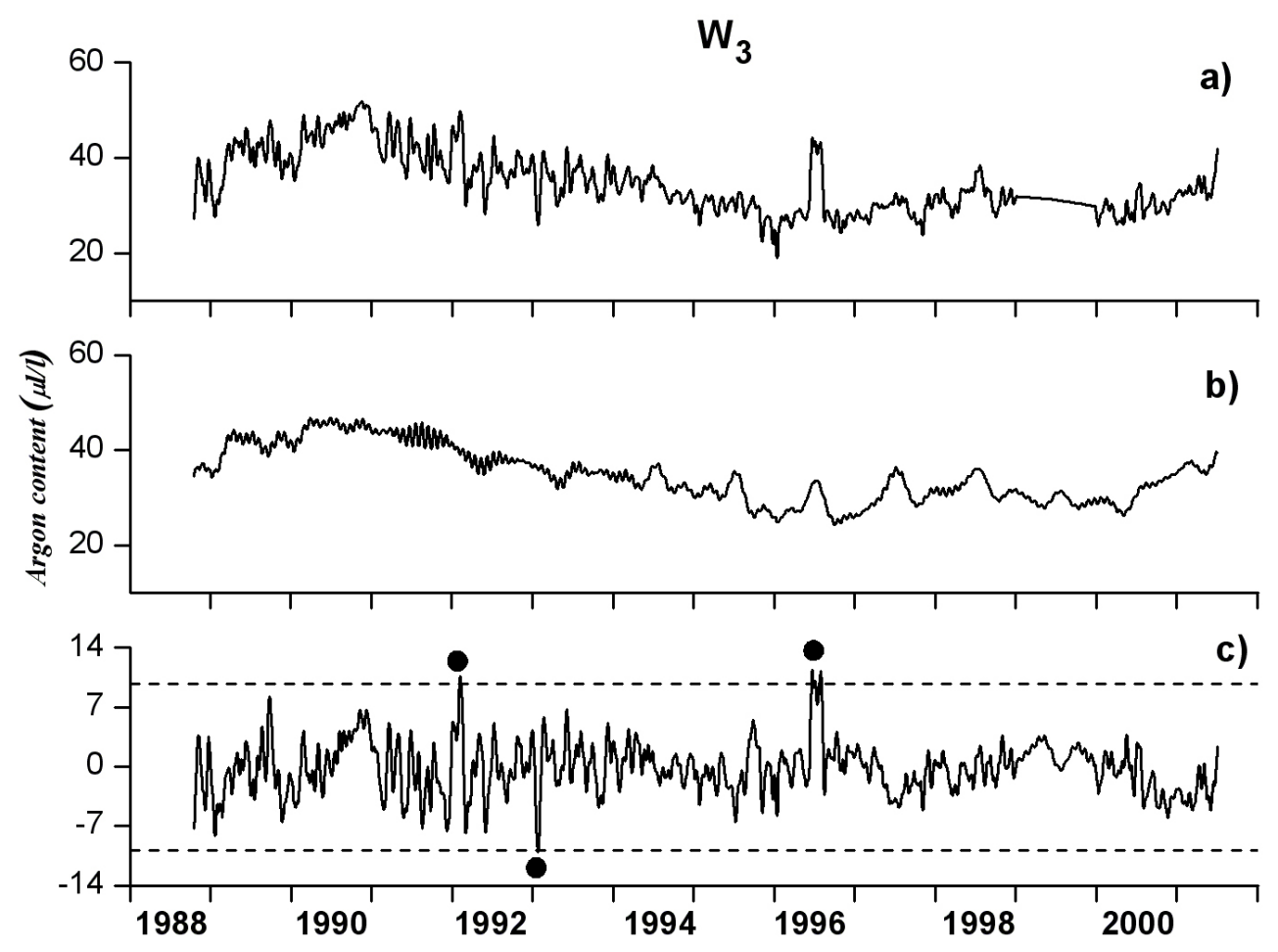

Fig. 4. Argon content at $W_{3}$ : (a) smoothed time-series (Fig. 2b); (b) long-meteo-tidal time-series; (c) residual time series (plot a - plot b). In the plot $\mathrm{c}$ the horizontal dashed lines represent the $\pm 3 \sigma$ level and the black circles indicate the out level zones.

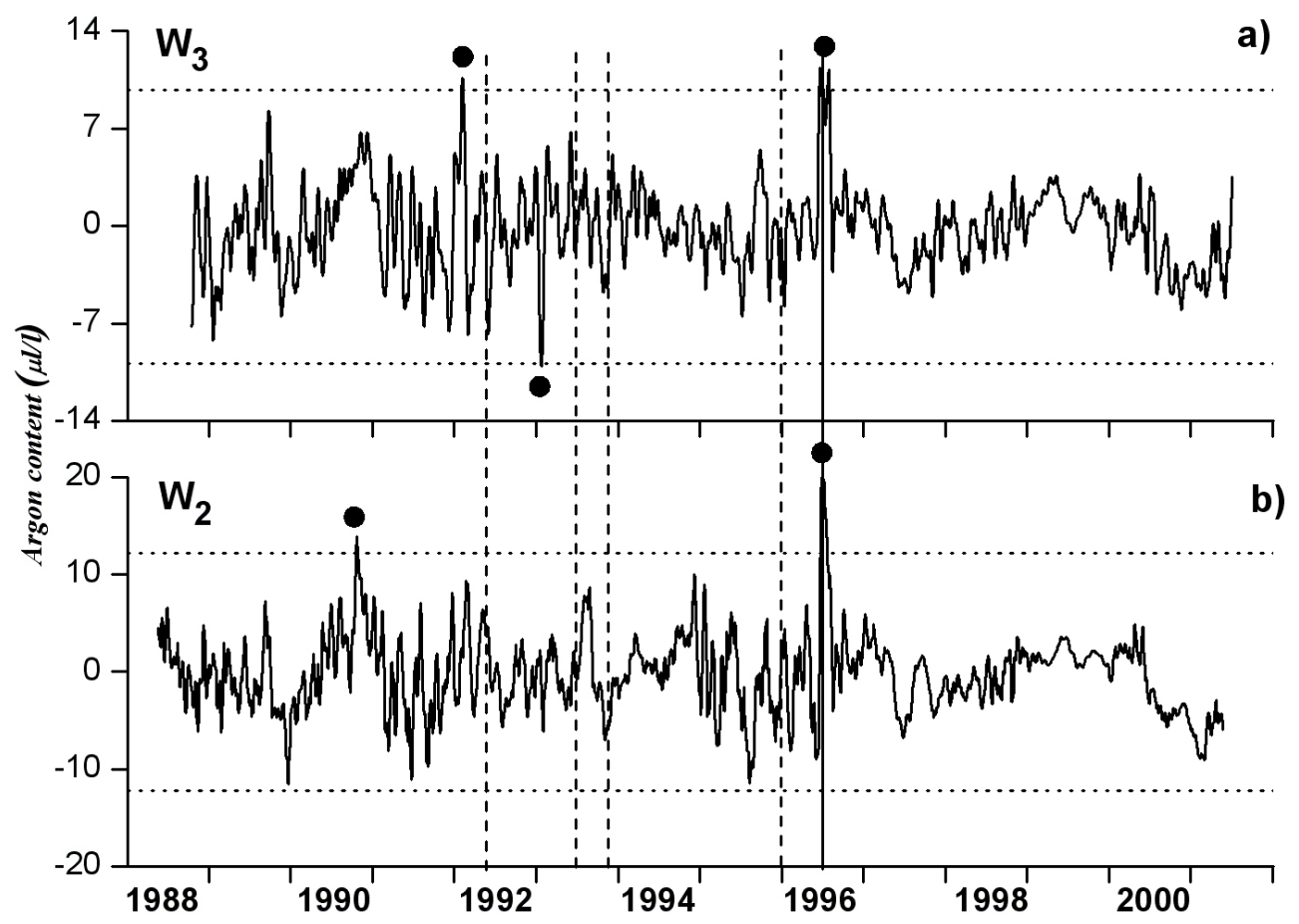

Fig. 5. (a) Residual time-series of Argon content at $W_{3}$ (plot c in Fig. 4); (b) residual time-series of Argon content at $W_{2}$. The horizontal dashed lines represent the $\pm 3 \sigma$ levels; the black circles indicate the out level zones. The vertical line indicates the occurrence of the 21 June 1996 earthquake; the vertical dashed lines indicate the occurrence of the other four earthquakes shown in Fig. 1. 


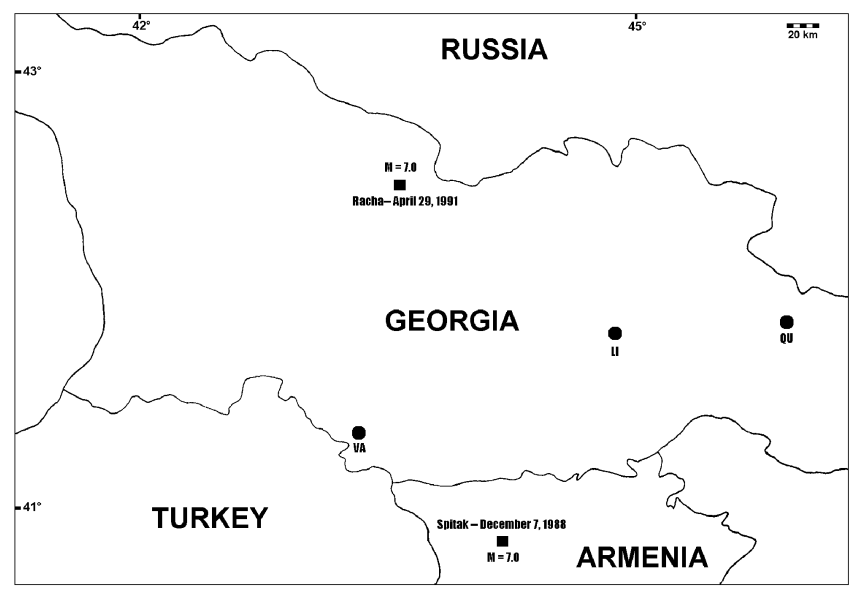

Fig. 6. Map showing the Caucasus and the location of the springs (LI, QU and VA) where the Helium content data were collected. The epicentres of the Spitak and the Racha earthquake, with the indication of magnitude and occurrence dates, are also shown.

dashed lines. From Fig. 4c three out levels, indicated by black circles, stand out; one of these in correspondence of the increase appearing clearly in the raw and smoothed data (Fig. 2).

Then, we look the Argon content data collected at $W_{2}$ using the same analysis method and we obtained very similar results. The final result, that is the residual trend with the relative $\pm 3 \sigma$ level, is shown in Fig. 5b. From Fig. $5 b$ two out levels appear. In Fig. 5a the residual time-series of Argon content at $W_{3}$ (plot c of Fig. 4) is shown. Finally, we compared the time occurrence of the out levels at the two wells (Fig. 5) and we found out that a coincidence exists only in one case. This case matches with the increase in the Argon content during June-July 1996 pointed out previously for $W_{3}$ (Fig. 2) and in Biagi et al. (1999) for $W_{2}$.

\section{Discussion}

The residual trends of the Argon content at the two wells present some part over the $\pm 3 \sigma$ level that should represent effective large anomalous variations. Such variations probably are related to some particular meteorological situation, to some local settlement of the water-bearing stratum or to some local/large tectonic process. But, if we select as an anomaly only the case in which a time coincidence in the out levels data exists at the two different wells, the local processes should be debarred. In such a case the anomaly could be justified only with some particular meteorological situation or some large tectonic process. This is the case of the out levels of the Argon content at $W_{2}$ and $W_{3}$ pointed out during JuneJuly 1996. The duration of these out levels ranges from 38 to 50 days with a difference of six days in the beginning. From now onwards we consider these two out levels as an unique anomaly. The analysis of the meteorological data collected in the Petropavlosk area did not reveal any particular situation
Table 2. Focal depth of the earthquakes indicated in Fig. 1.

\begin{tabular}{rc}
\hline $\begin{array}{c}\text { Earthquake } \\
\text { (occurrence time) }\end{array}$ & $\begin{array}{c}\text { Focal depth } \\
(\mathrm{km})\end{array}$ \\
\hline 2 March 1992 & 32 \\
8 June 1993 & 40 \\
13 November 1993 & 50 \\
1 January 1996 & 10 \\
21 June 1996 & 1 \\
\hline
\end{tabular}

during the appearance of this anomaly. So, it is reasonable to look for some large tectonic process. During May-July 1996 no particular volcanic activity happened in southern part of the Kamchatka peninsula. The only large tectonic process was the occurrence of the earthquake on 21 June 1996 with $M=7.1$ at a distance less than $250 \mathrm{~km}$ from the wells. The time occurrence of this earthquake is indicated in Fig. 5 by a vertical line. In this connection a 7-13 days premonitory phase in the Argon anomaly appears. So, a seismic precursor could be detected.

In order to validate this possibility, we checked the seismic activity occurred in the zone during the time of the measurements. We found out four more strong earthquakes $(M>6.5)$ occurred at distances within $250 \mathrm{~km}$ from the wells. The location of the epicentres together with the indication of occurrence dates and of magnitude is shown in Fig. 1. The focal depth of all the five earthquakes we considered is reported in Table 2. Dashed vertical lines indicate the time occurrence of these earthquakes in Fig. 5 and no anomaly in the Argon content data corresponds to such cases. Then, we examined the focal depth (Table 2) of all the five earthquakes and we discovered that only one was very shallow, that is the earthquake we connected previously with our anomaly. This coincidence could be significant, but it needs some confirmation. In the past, some of the authors of this paper analysed the Helium content data collected with a sampling frequency of one day in natural springs of the Caucasus during seven years (Areshidze et al., 1992a, b; Bella et al., 1995). In this time interval the destructive Spitak and Racha earthquakes took place at distances less than $200 \mathrm{~km}$ from three springs (LI, VA, QU), the location of them is shown in Fig. 6. The springs are located in thermal zones; their water temperature ranges from $30^{\circ} \mathrm{C}(\mathrm{QU})$ to $56^{\circ} \mathrm{C}(\mathrm{VA})$ and the water flows from depths ranging from $1000 \mathrm{~m}$ to $2500 \mathrm{~m}$. The epicentre, occurrence date and magnitude of the previous two earthquakes are also indicated in Fig. 6. The three Helium content time-series with the indication of the time occurrences of the two earthquakes are reported in Fig. 7. In that analysis only a low-pass FFT filter (in order to reduce the occurrence of casual errors in the measurements) was applied to the raw data before using the $3 \sigma$ criterion. In fact the external processes as the meteorology and the gravity tides on the water of natural springs (Caucasus) are not so influent as on the water 


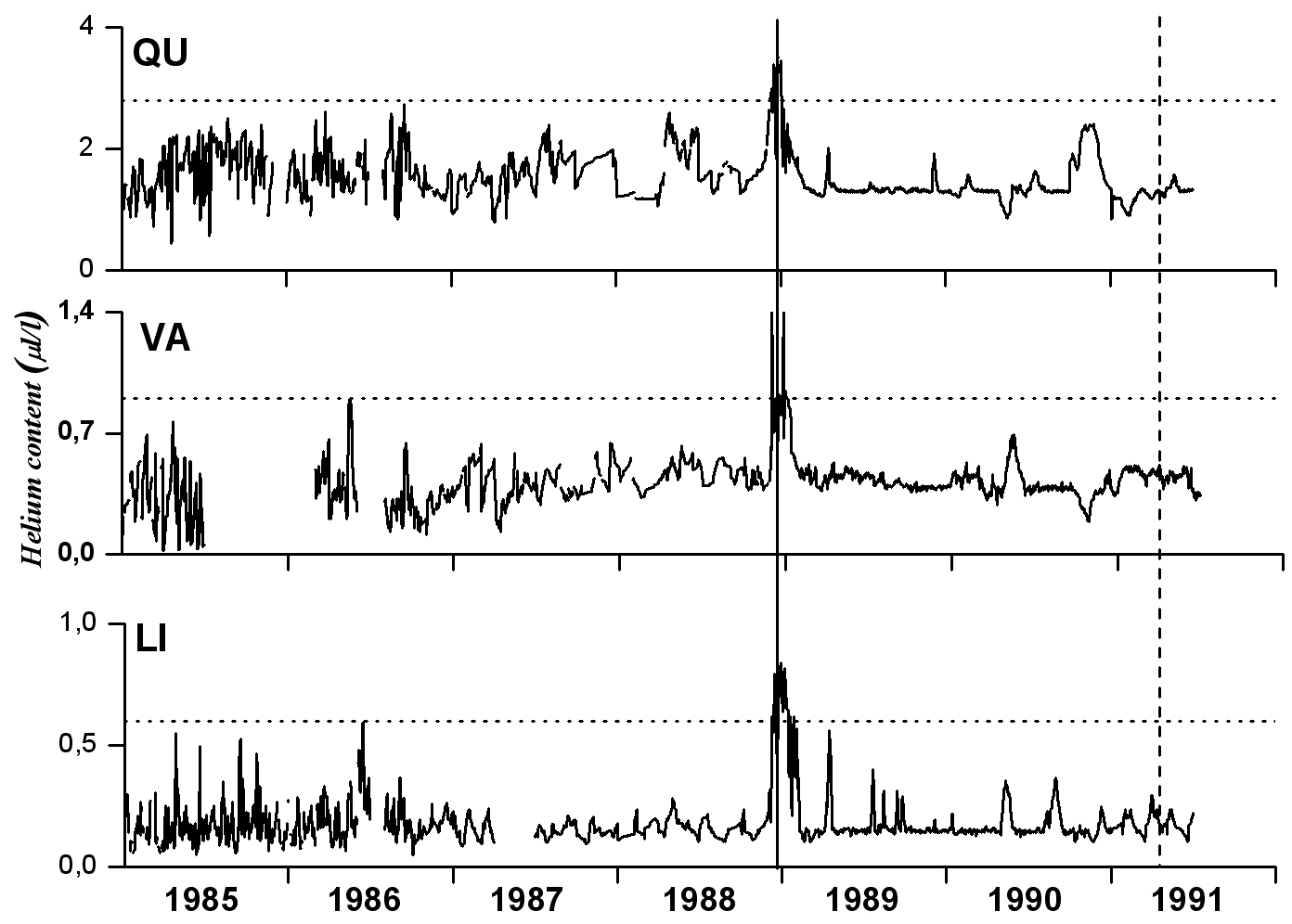

Fig. 7. Smoothed (smoothing window of five days) time-series of Helium content at three springs (LI, QU and VA) from 1 January 1985 to 30 June 1991. The horizontal lines represent the $+3 \sigma$ level. The vertical line indicates the occurrence of the Spitak earthquake; the vertical dashed line indicates the occurrence of the Racha earthquake.

of wells (Kamchatka). From Fig. 7 clear simultaneous out levels (over the $3 \sigma$ level) stand out on the occasion of the Spitak earthquake while none out level appears on the occasion of the Racha event. The duration of the out levels ranges from 28 to 42 days and a premonitory phase of 2-6 days exists (Bella et al., 1995). Looking at the focal depth of the two previous earthquakes we discovered that for the Spitak event it was $2-4 \mathrm{~km}$, while for the Racha event a value greater than $10 \mathrm{~km}$ is considered (Seismological Notes, 1986-1991; Bella et al., 1995).

The coincidence with the phenomenology pointed out in the Caucasus validates the interpretation as a seismic precursor of the Kamchatkian anomaly we presented.

\section{Conclusions}

At first, this study pointed out that an evident groundwater gas content anomaly in the raw data collected at a single place can became more questionable if a strict data analysis for removing known external effects, is carried out. But, if the anomaly remains after the analysis and if a temporal coincidence appears with an anomaly in the same parameter revealed at another site, the meaning of these anomalies is enlarged and the possibility that they are related to some shallow earthquake is supported. Then, this study confirms that the probability of revealing premonitory anomalies in groundwater gases content increases strongly if the forthcoming earthquake is shallow. This result seems reasonable: in fact, if gases emanations happen during the preparatory phase of an earthquake, the diffusion can occur easily in the surface underground strata, where the porosity is large, while a diffusion from the depth does not occur easily. In addition, in the first case, an all wards propagation should occur permitting the appearance of anomalies simultaneously at different sites.

Acknowledgements. This research was partly conducted in the framework of the NATO Collaborative Linkage Grant 978641.

Edited by: M. E. Contadakis

Reviewed by: G. Martinelli and two other referees

\section{References}

Areshidze, G., Bella, F., Biagi, P. F., Caputo, M., Chkuaseli, V., Della Monica, G., Ermini, A., Manjgaladze, P., Melikadze, G., Sgrigna, V., Slavina, L., and Zilpimiani, D.: Anomalies in geophysical and geochemical parameters revealed on the occasion of the Paravani $(M=5.6)$ and Spitak $(M=6.9)$ earthquakes (Caucasus), Tectonophysics, 202, 23-41, 1992a.

Areshidze, G., Bella, F., Biagi, P. F., Caputo, M., Della Monica, G., Ermini, A., Manjgaladze, P., Melikadze, G., Sgrigna, V., and Zilpimiani, D.: No preseismic evidence from hydrogeochemi- 
cal parameters on the occasion of the 29 April 1991 Georgian earthquake, Caucasus, Tectonophysics, 213, 353-358, $1992 \mathrm{~b}$.

Barsukov, V. L., Serebrennikov, V. S., Varsha, G. M., and Garanin, A. V.: Geochemical methods for earthquake prediction, Geokhim., 3, 327-337, 1979.

Barsukov, V. L., Varshal, G. M., and Zamokina, N. S.: Recent results of hydrogeochemical studies for earthquake prediction in USSR, Pure Appl. Geophys. 122, 143-156, 1984/85.

Bella, F., Biagi, P. F., Caputo, M., Cozzi, E., Della Monica, G., Ermini, A., Plastino, W., Sgrigna, V., and Zilpimiani, D.: Helium content in thermal waters in the Caucasus from 1985 to 1991 and correlations with the seismic activity, Tectonophysics, 246, 263 278, 1995.

Biagi, P. F., Bella, F., Scandone, R., Cozzi, E., Ermini, A., Kingsley, S. P., Anderson, C. W., Derlien, P. J., Khatkevich, Y. M., and Gordeev, E. I.: Groundwater argon content on the occasion of strong earthquakes in a seismogenetic area of Kamchatka (Russia), Il Nuovo Cimento C, 22, 503-508, 1999.
Biagi, P. F., Ermini, A., Kingsley, S. P., Khatkevich, Y. M., and Gordeev, E. I.: Groundwater ion content precursors of strong earthquakes in Kamchatka (Russia), Pageoph, 157, 302-320, 2000.

Gorbatov, A., Kostoglodov, V., Suarez, G., and Gordeev, E.: Seismicity and structure of the Kamchatka subduction zone, J. Geophys. Res., 102, 17 883-17 898, 1997.

King, C. Y., Evans, W. C., Presser, T., and Husk, R. H.: Anomalous chemical changes in well waters and possible relation to earthquakes, Geophys. Res. Lett., 8, 425-428, 1981.

King, C. Y.: Gas geochemistry applied to earthquake prediction: An overview, J. Geophys. Res., 91, 12 269-12 281, 1986.

Seismological Notes of the Institute of Geophysics, Academy of Sciences of the Georgian SSR, Tbilisi, Georgia, 1986-1991.

Thomas, D.: Geochemical precursors to seismic activity, Pure Appl. Geophys., 126, 241-265, 1988.

Wakita, H., Nakamura, Y., and Sano, Y.: Short-term and intermediate-term geochemical precursors, Pure Appl. Geophys.,126, 267-278, 1988. 